\title{
Effect of Preheating Temperature on Microstructure and Optical Properties of ZnO Thin Films Prepared by Sol-Gel Spin Coating Technique
}

\author{
QIANG-Min $\mathrm{JI}^{a}$, YA-Li $\mathrm{WANG}^{b}$, XIAO-YONG GAO ${ }^{a, *}$, HuI GAO ${ }^{a}$ AND YAO-FEI Zhai ${ }^{a}$ \\ ${ }^{a}$ The Key Laboratory of Material Physics of Ministry of Education, School of Physics and Engineering, \\ Zhengzhou University, Zhengzhou 450052, China \\ ${ }^{b}$ Department of Physics, Zhengzhou Normal University, Zhengzhou 450044, China
}

(Received January 4, 2016)

\begin{abstract}
Highly-oriented $\mathrm{ZnO}$ thin films prepared by using low-cost technique such as sol-gel technique are of much importance to $\mathrm{ZnO}$-based white light-emitting diodes. The chose of proper preheating temperature in sol-gel technique is still critical for highly-oriented $\mathrm{ZnO}$ thin film so far. The mechanisms for the preheating in the formation of $\mathrm{ZnO}$ thin film and for the reactions involved in the sol solution have not been clearly stated yet. Thus, in this work, the highly-oriented $\mathrm{ZnO}$ thin films were prepared on glass substrates by using sol-gel spincoating technique. The sol solution was prepared by using the two-step method rather than usual one-step method, which facilitates the understanding of the mechanism for the reactions involved in the sol solution. The effect of the preheating temperature on the microstructure and the optical properties of the films were in particular investigated. The mechanisms for the preheating in the formation of the films and for the reactions involved in the sol solution prepared by the two-step method were also proposed in terms of the experimental results. The preheating not only enhances the volatilization of the solvent 2-methoxyethanol and the decomposition of the residual organic species, but also results into the formation of small number of $\mathrm{ZnO}$ particles. The preheating temperature of $300^{\circ} \mathrm{C}$ is most favorable for the highly-oriented $\mathrm{ZnO}$ thin film. Increasing the preheating temperature results into the blue shift of the absorption edges of the films. This can be explained by using the quantum-size effect. The photoluminescence spectra of the films show an UV emission at the near-band edge and a broad green-yellow emission at 470-620 nm. The former is closely related to the excitons, while the latter is to the intrinsic defect species in the film.
\end{abstract}

DOI: 10.12693/APhysPolA.129.1191

PACS/topics: 78.55.Et, 78.55.-m

\section{Introduction}

In recent years, study on the $\mathrm{ZnO}$ is increasingly attractive because $\mathrm{ZnO}$ has a direct wide-band gap of $3.37 \mathrm{eV}$ and a large exciton binding energy of approximately $60 \mathrm{meV}[1,2]$. Owning to its excellent physical properties, $\mathrm{ZnO}$ has been a promising material in piezoelectric and optoelectronic fields [3]. $\mathrm{ZnO}$ thin films are widely used to light-emitting diodes (LED) [4], UV sensors [5, 6], solar cells [7, 8], surface acoustic wave (SAW) devices and optical wave-guide devices as well [9]. It is well known that $\mathrm{ZnO}$ thin films can be prepared by variety of techniques such as sputtering [10, 11], laser ablation [12-14], chemical vapor deposition $[15,16]$ and sol-gel spin-coating technique [17-21]. Among the above techniques, sol-gel spin-coating technique is relatively appealing and commercially favorable for the preparation of highly-oriented $\mathrm{ZnO}$ thin films because of its low cost, well control over the chemical composition of the thin film, the capability of preparing large-size homogeneous thin film and large freedom of choosing dopant as well.

The preparation of $\mathrm{ZnO}$ thin films by using solgel spin-coating technique has been reported previously.

*corresponding author; e-mail: xygao@zzu.edu.cn
Kim et al. [19] hold the opinion that $\mathrm{ZnO}$ thin film obtained by preheating the sol solution at $275^{\circ} \mathrm{C}$ and following a post-heating at $650^{\circ} \mathrm{C}$ for one hour is highly $\langle 002\rangle$-oriented by using low boiling point organic solvent like isopropanol. Santos and Santos [22] studied the relationship between the preheating temperature and the post-annealing temperature in the sol-gel spincoating processing in order to obtain highly-oriented $\mathrm{ZnO}$ thin film. Their result demonstrates that lower preheating temperature requires higher post-annealing temperature and longer post-annealing time. The highlyoriented $\mathrm{ZnO}$ thin film was prepared by using a preheating temperature of $120^{\circ} \mathrm{C}$ and a post-heating temperature of $350^{\circ} \mathrm{C}$. Ohyama et al. [23] varied the preheating temperature from 200 to $500^{\circ} \mathrm{C}$ and post-annealing temperature from 500 to $800^{\circ} \mathrm{C}$, founding that the best $\mathrm{ZnO}$ thin film was achieved by using a preheating temperature of $300{ }^{\circ} \mathrm{C}$. Bao et al. [24] also studied the orientation of the $\mathrm{ZnO}$ thin film by varying the annealing temperature from 400 to $600^{\circ} \mathrm{C}$, however, they did not achieve a good result.

Although effect of the preheating temperature on the $\langle 002\rangle$ preferential orientation and the optical properties of $\mathrm{ZnO}$ thin films have been studied previously, an equivocal and even ambivalent result was reported. An agreement on the relationship between the preheating and the post-annealing in the sol-gel spin-coating preparation of highly-oriented $\mathrm{ZnO}$ thin films has not been reached 
so far. The uniform distribution of nanoscaled refining $\mathrm{ZnO}$ particles and wrinkle on the film surface is not previously reported for $\mathrm{ZnO}$ film prepared by sol-gel spincoating technique. In addition, the mechanisms for the preheating in the formation of the films and for the reactions involved in the sol solution have not been clearly stated yet because the usual preparation of the sol solution uses the one-step method by which the precursor zinc source and stabilizer are dissolved into the organic solvent at the same time. In the one-step method, no white $\mathrm{Zn}(\mathrm{OH})_{2}$ precipitation was observed. This makes it difficult to understand the reactions involved in the sol solution. In the present investigation, we have prepared the highly-oriented $\mathrm{ZnO}$ thin films on glass substrates by using sol-gel spin-coating technique. The sol solution is prepared by using the two-step method rather than usual one-step method to facilitate the understanding of the mechanism of reactions involved in the sol solution. The post-annealing temperature was chosen as $400^{\circ} \mathrm{C}$ in terms of the thermogravimetry (TG)-differential thermal analysis (DTA) result [25]. The complete decomposition of residual $\mathrm{ZnO}$-based organic complex is conducted and a large number of $\mathrm{ZnO}$ nanoparticles are generated near $400^{\circ} \mathrm{C}$. Thus, the post-annealing temperature of the films was reasonably determined as $400^{\circ} \mathrm{C}$ in order to study the effect of the preheating. The mechanisms for the preheating in the formation of the films and for the reactions involved in the sol solution prepared by the two-step method were also proposed in terms of the experimental result. This work will give us a valuable insight into the key role the preheating plays in the formation of $\mathrm{ZnO}$ thin film. The results can also provide important support for the preparation of highly-oriented $\mathrm{ZnO}$ thin film and $\mathrm{ZnO}$-based light-emitting devices simultaneously.

\section{Experimental}

\subsection{Preparation of the $\mathrm{ZnO}$ thin films}

A sol solution was prepared by using the twostep method before the preparation of the $\mathrm{ZnO}$ thin films. The preparation of the sol solution includes two steps. First, zinc acetate dehydrate $\left(\mathrm{Zn}\left(\mathrm{CH}_{3} \mathrm{COO}\right)_{2}\right.$. $2 \mathrm{H}_{2} \mathrm{O}$ ) of $6.585 \mathrm{~g}$ was added to 2-methoxyethanol solvent $\left(\mathrm{CH}_{3} \mathrm{OCH}_{2} \mathrm{CH}_{2} \mathrm{OH}\right)$ of approximately $48 \mathrm{ml}$ and then stirred at $60^{\circ} \mathrm{C}$ for one hour. Some white $\mathrm{Zn}(\mathrm{OH})_{2}$ precipitations in the form of particles were clearly formed. Second, stabilizer ethanolamine $\left(\mathrm{HOCH}_{2} \mathrm{CH}_{2} \mathrm{NH}_{2}\right.$, i.e. MEA) of approximately $1.8 \mathrm{ml}$ was then added to the above complex solution and stirred at $60^{\circ} \mathrm{C}$ for another one hour until a transparent and homogeneous sol solution was obtained. The two-step method can facilitate the understanding of the mechanism of reactions involved in the sol solution than usual one-step method. The glass substrates used were precleaned with acetone in ultrasonic cleaner for $20 \mathrm{~min}$, washed with alcohol for $10 \mathrm{~min}$, and finally dried in the drying case. The $\mathrm{ZnO}$ thin films were prepared on clean glass substrates with the prepared sol solution by using sol-gel spin-coating technique. The flowchart of the preparation of the $\mathrm{ZnO}$ thin film is presented in Fig. 1. The post-annealing temperature of $400^{\circ} \mathrm{C}$ was chosen in terms of the TG-DTA result.

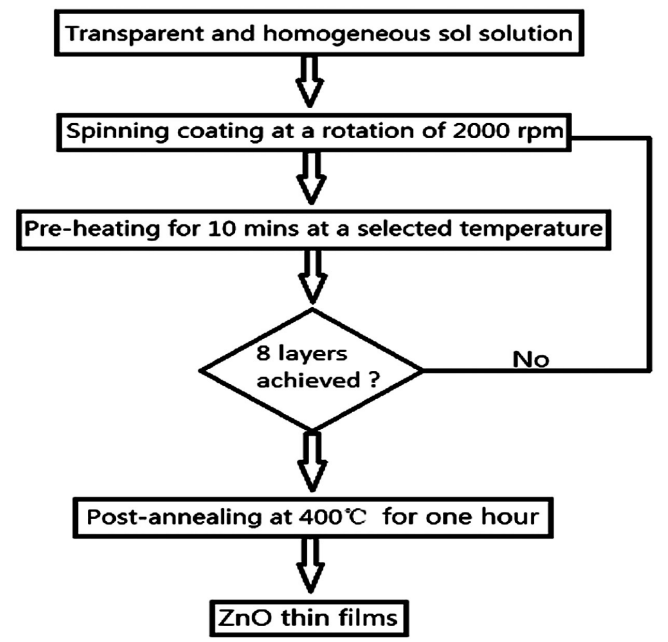

Fig. 1. Flowchart of the preparation of the $\mathrm{ZnO}$ thin films by using the sol-gel spin-coating technique.

\subsection{Characterization techniques}

The microstructure of the $\mathrm{ZnO}$ thin films was characterized with the use of an X-ray diffractometer (Philip PANalytical X'pert, $\lambda=0.15405 \mathrm{~nm}$ for $\mathrm{Cu} K_{\alpha}$ radiation) and a cold-field scanning electron microscope (SEM, JSM-6060). The reflectance and transmittance spectra of the thin films were measured by using an ultravioletvisible-near infrared spectrophotometer (Shimadzu Company, UV-3150). The optical band gap value of the films was fitted by using the transmittance data. The photoluminescence spectra of the thin films were obtained from a fluorescent spectrometer (FluoroMax-4). The thickness of the films was determined in terms of the light interference in the reflectance spectra. All the measurements were conducted at room temperature.

\subsection{Mechanism for the reactions involved}

in the sol solution prepared by the two-step method

The preparation of the sol solution includes two steps. First, zinc acetate dehydrate was added to 2-methoxyethanol solvent and then stirred at $60^{\circ} \mathrm{C}$ for one hour. Some white $\mathrm{Zn}(\mathrm{OH})_{2}$ precipitations in the form of particles are clearly observed. This indicates that zinc acetate dehydrate is hydrolyzed to $\mathrm{Zn}(\mathrm{OH})_{2}$ in 2-methoxyethanol solvent. The reactions involved at this stage can be described as two reversible hydrolysis reactions (1) and (2). Second, stabilizer MEA was then added to the complex solution and stirred at $60^{\circ} \mathrm{C}$ for another one hour. The $\mathrm{Zn}(\mathrm{OH})_{2}$ precipitations are dissolved with aid of MEA and a transparent and homogeneous sol solution was finally obtained. Here, stabilizer MEA plays dual roles. On the one hand, MEA can easily combine with $\mathrm{H}^{+}$and make the complex solution be alkaline, which can also accelerate the reversible 
reaction (1) along the hydrolysis direction. On the other hand, MEA can chelate with $\mathrm{Zn}^{2+}$, which also accelerate the reversible reaction (1) along the hydrolysis direction. At this stage, the reactions involved can be described by reactions (1) to (4). Reactions (3) and (4) are chelation reaction of MEA and fasculation of $\mathrm{Zn}(\mathrm{OH})_{2}$, respectively. Thus, the final transparent sol solution is mainly composed of soluble $\mathrm{H}-\mathrm{O}-(\mathrm{Zn}-\mathrm{O}-\mathrm{Zn})_{n^{-}}$ $\mathrm{O}-\mathrm{H}$ besides 2-methoxyethanol solvent. A small number of $\mathrm{Zn}(\mathrm{OH})\left(\mathrm{CH}_{3} \mathrm{COO}\right),\left[\mathrm{Zn}(\mathrm{OH}) \mathrm{CH}_{2} \mathrm{CH}_{2} \mathrm{NH}_{2}\right]^{2+}$ and MEA etc. also exist in the sol solution.

$$
\begin{aligned}
& 2 \mathrm{Zn}\left(\mathrm{CH}_{3} \mathrm{COO}\right)_{2}+\mathrm{H}_{2} \mathrm{O} \longleftrightarrow \mathrm{Zn}(\mathrm{OH})\left(\mathrm{CH}_{3} \mathrm{COO}\right) \\
& +\mathrm{CH}_{3} \mathrm{COOH}+\mathrm{Zn}^{2+}+2 \mathrm{CH}_{3} \mathrm{COO}^{-}, \\
& \mathrm{Zn}(\mathrm{OH})\left(\mathrm{CH}_{3} \mathrm{COO}\right)+\mathrm{H}_{2} \mathrm{O} \longleftrightarrow \\
& \quad \mathrm{Zn}(\mathrm{OH})_{2}+\mathrm{CH}_{3} \mathrm{COOH}, \\
& \mathrm{Zn}^{2+}+\mathrm{HOCH}_{2} \mathrm{CH}_{2} \mathrm{NH}_{2} \longleftrightarrow \\
& \quad\left[\mathrm{Zn}(\mathrm{OH}) \mathrm{CH}_{2} \mathrm{CH}_{2} \mathrm{NH}_{2}\right]^{2+}, \\
& \mathrm{Zn}(\mathrm{OH})_{2}+\mathrm{Zn}(\mathrm{OH})_{2} \longleftrightarrow \mathrm{H}-\mathrm{O}-\mathrm{Zn}-\mathrm{O} \\
& \quad-\mathrm{Zn}-\mathrm{O}-\mathrm{H}+\mathrm{H}_{2} \mathrm{O} .
\end{aligned}
$$

\section{Results and discussion}

\subsection{Structural properties}

Figure 2 shows the X-ray diffraction (XRD) patterns of the $\mathrm{ZnO}$ thin films obtained by preheating the sol at different temperatures for $10 \mathrm{~min}$. No further postannealing was performed. The preheating time of $10 \mathrm{~min}$ chosen in terms of the previous investigation is enough to the volatilization of the solvent and the decomposition of some residual organic species. Seen from Fig. 2, a weak broad diffraction peak was observed at near $35^{\circ} \mathrm{C}$ in all the XRD spectra of the films. Above $200^{\circ} \mathrm{C}$, the (100) diffraction peak disappears. The broad diffraction peak indicates that the small number of $\mathrm{ZnO}$ crystallites with crystallite size of about $7-11 \mathrm{~nm}$ are produced and randomly distributed in the amorphous net. Notably, the $\langle 002\rangle$ orientation of the films are weakened above $350^{\circ} \mathrm{C}$, indicating that the preheating temperature above $350^{\circ} \mathrm{C}$ is harmful to the preparation of the highly-oriented $\mathrm{ZnO}$ film and that using the preheating alone is difficult to obtain highly-oriented $\mathrm{ZnO}$ thin film.

Figure 3 shows the XRD patterns of the $\mathrm{ZnO}$ films obtained by preheating the sol at different temperatures for $10 \mathrm{~min}$ and then following a post-annealing at $400{ }^{\circ} \mathrm{C}$ for one hour. Seen from Fig. 3, when the preheating temperature is $150{ }^{\circ} \mathrm{C}$ and $200^{\circ} \mathrm{C}$, the broad diffraction peak in Fig. 2 was decomposed into three sharp diffraction peaks corresponding to the diffraction of the $\mathrm{ZnO}$ (100), (002) and (101) crystal faces after the $\mathrm{ZnO}$ film was post-annealed at $400{ }^{\circ} \mathrm{C}$ for one hour. The intensities of the three diffraction peaks initially have a slight difference, indicating that the $\mathrm{ZnO}$ film is initially polycrystalline and not $\langle 002\rangle$ oriented. However, with further increasing the preheating temperature until $300^{\circ} \mathrm{C}$, the intensity of the (002) diffraction

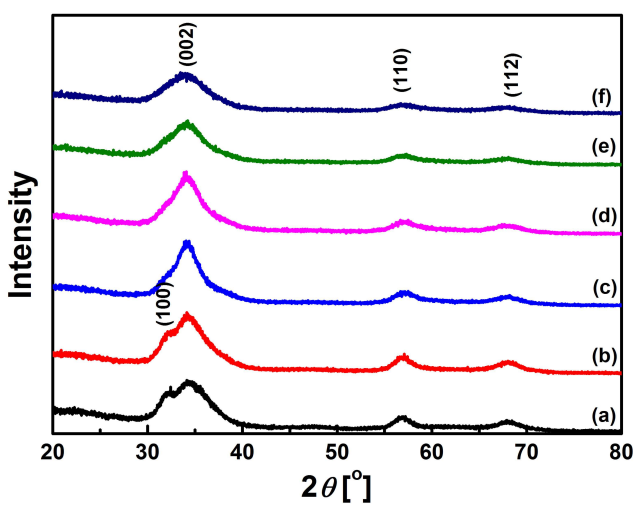

Fig. 2. XRD patterns of the $\mathrm{ZnO}$ thin films obtained by preheating the sol at temperatures (a) $150^{\circ} \mathrm{C}$, (b) $200^{\circ} \mathrm{C}$, (c) $250{ }^{\circ} \mathrm{C}$, (d) $300^{\circ} \mathrm{C}$, (e) $350{ }^{\circ} \mathrm{C}$ and (f) $400^{\circ} \mathrm{C}$ for $10 \mathrm{~min}$.

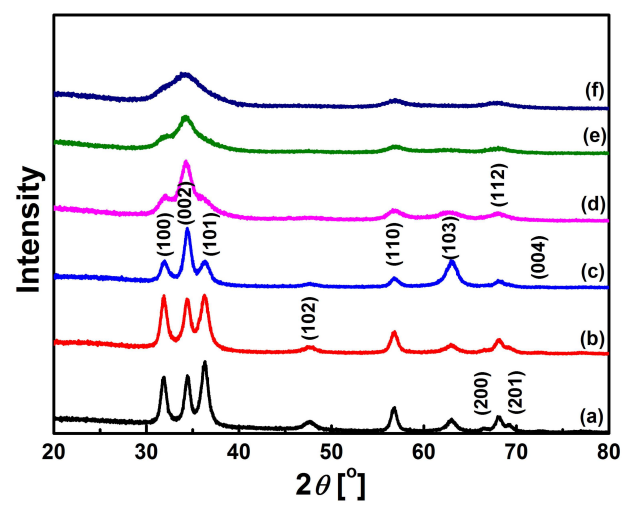

Fig. 3. XRD patterns of the $\mathrm{ZnO}$ thin films obtained by preheating the sol at temperatures (a) $150{ }^{\circ} \mathrm{C}$, (b) $200{ }^{\circ} \mathrm{C}$, (c) $250{ }^{\circ} \mathrm{C}$, (d) $300^{\circ} \mathrm{C}$, (e) $350{ }^{\circ} \mathrm{C}$, and (f) $400^{\circ} \mathrm{C}$ for $10 \mathrm{~min}$ and then following a post-annealing at $400^{\circ} \mathrm{C}$ for one hour.

peak is strongly enhanced compared with those of the (100) and (101) diffraction peaks. This indicates that the $\langle 002\rangle$ preferred orientation is enhanced with increasing the preheating temperature and is reached strongest at $300^{\circ} \mathrm{C}$. The $(002)$ diffraction peak, however, begins to become weak and broad at the preheating temperature over $300^{\circ} \mathrm{C}$. This indicates that the preheating temperature over $300^{\circ} \mathrm{C}$ is harmful to the preparation of the highly-oriented $\mathrm{ZnO}$ thin films. In this work, the low boiling points of the solvent 2-methoxyethanol and the stabilizer agent $\mathrm{MEA}$ are $124.5^{\circ} \mathrm{C}$ and $170^{\circ} \mathrm{C}$, respectively. The thermal decomposition temperature of the zinc acetate is $240^{\circ} \mathrm{C}$ [26]. However each kind of the reagent in the sol and gel probably may not have its boiling point. Thus, when preheating the samples at the preheating temperature below $250^{\circ} \mathrm{C}$, some residual organic species may still exist in the film before the post-annealing. As a result, the decomposition of some residual organic species, and the generation and growth of number of $\mathrm{ZnO}$ crystallites take place at the same time during the post-annealing. 
The decomposition of the residual organic species may strongly influence the $\langle 002\rangle$ preferred orientation and the growth of the $\mathrm{ZnO}$ crystallites. When preheating the sol at $250^{\circ} \mathrm{C}$ and $300^{\circ} \mathrm{C}$, based on the above TG-DTA result, the residual organic species in the film was almost decomposed. The generation and growth of the $\mathrm{ZnO}$ crystallites mainly occurs in the following post-annealing. However, when the preheating temperature is above $300^{\circ} \mathrm{C}$, the $\mathrm{ZnO}-(002)$ diffraction peak begins to be weak and wide, indicating that the crystallite size becomes small and the distribution of the crystallite becomes random. This is probably due to the rapid volatilization of the solvent and the rapid decomposition of the residual organic species at this stage at which the preheating temperature have resulted into the generation of some randomly-distributed $\mathrm{ZnO}$ crystallites. Thus, the post-annealing at $400^{\circ} \mathrm{C}$ almost has no obvious help for the crystallization of the $\mathrm{ZnO}$ at the preheating temperature over $300^{\circ} \mathrm{C}$. The preheating temperature of $300^{\circ} \mathrm{C}$ is proper to the preparation of the highly-oriented $\mathrm{ZnO}$ thin films by affecting the volatilization of the solvent, the rapid decomposition of the residual organic species and the generation of $\mathrm{ZnO}$ crystallites [19, 27, 28].

Figure 4 shows the SEM images for the $\mathrm{ZnO}$ thin films obtained by preheating the sol for $10 \mathrm{~min}$ at different preheating temperatures and then following a postannealing at $400^{\circ} \mathrm{C}$ for one hour. At the preheating temperature below $250^{\circ} \mathrm{C}$, it is observed that a uniform $\mu$-scaled wrinkle is covered with the film surface. The film surface is more helpful for the light-trapping of the $\mathrm{ZnO}$ film within the solar cells than usual uneven film surface. This result can be due to the shrinkage of the film arising from the decomposition of the residual organic species during the post-annealing. By comparison, when preheating above $250^{\circ} \mathrm{C}$, a uniform, dense and flattening film surface was obtained. The nanoscaled particles are uniformly distributed in the film. The refining particles uniformly distributed were not formed and reported before. In addition, no clear wrinkle is clearly observed. This indicates that the decomposition of the residual organic species is completely finished during the preheating above $250^{\circ} \mathrm{C}$. The film becomes denser and the particle with several $\mathrm{nm}$ scale tends to be refined with increase of the preheating temperature.

The crystallite size along the $\langle 002\rangle$ orientation calculated by the Debye-Scherrer formula was increased from 7.9 to $26.5 \mathrm{~nm}$ and then reduced from 26.5 to $8.2 \mathrm{~nm}$ with increase of the preheating temperature. The crystallite size reached the maxima at the preheating temperature of $250^{\circ} \mathrm{C}$. These results are the same as those reported by Kim et al. [19]. As a result, the crystallite size can be increased with increase of the preheating temperature until $250^{\circ} \mathrm{C}$. This indicates that the post-annealing does not disturb but enhances the preferred growth of the crystallites at low preheating temperature because of the minor damages to the net arising from the slow volatilization of the solvent and slow decomposition of the residual organic species during the preheating. By comparison, the high preheating temperature over $250^{\circ} \mathrm{C}$ can produce more damages to the net arising from the rapid volatilization of the solvent and rapid decomposition of the residual organic species that do not contribute to the preferred growth of the crystallites in the post-annealing process. Thus, the crystallite size was reduced with increase of the preheating temperature above $250^{\circ} \mathrm{C}[23,28]$.
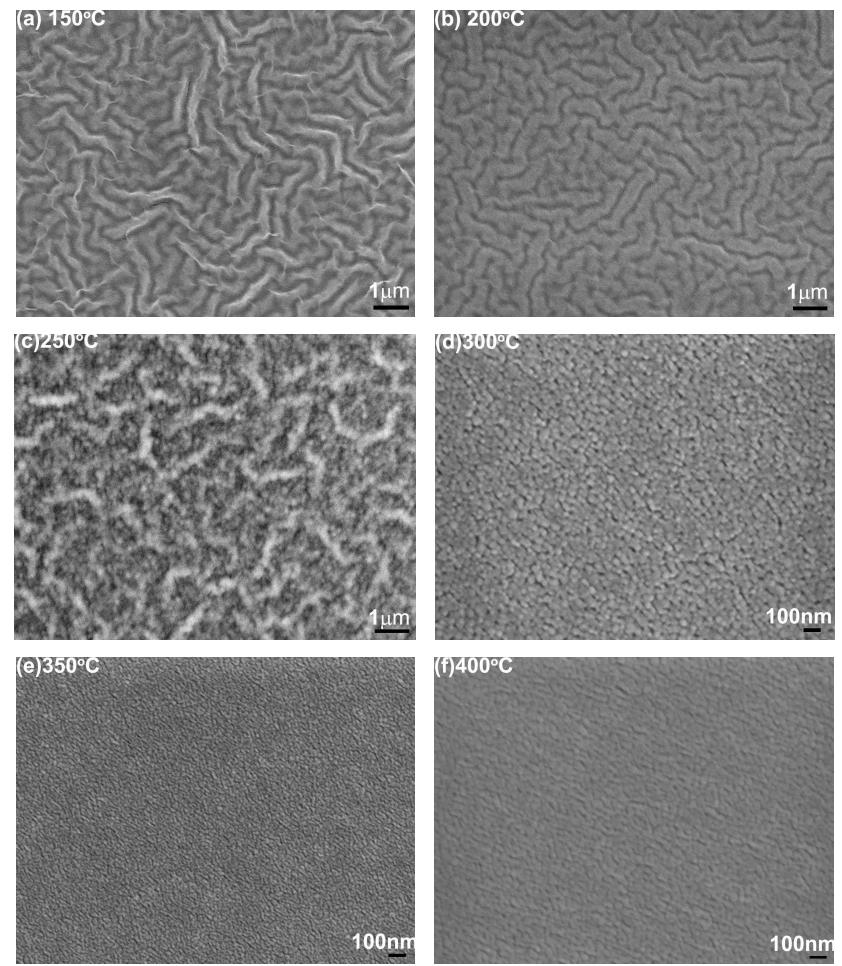

Fig. 4. SEM images of the $\mathrm{ZnO}$ thin films obtained by preheating the sol for $10 \mathrm{~min}$ at temperatures of (a) $150{ }^{\circ} \mathrm{C}$, (b) $200^{\circ} \mathrm{C}$, (c) $250^{\circ} \mathrm{C}$, (d) $300^{\circ} \mathrm{C}$, (e) $350{ }^{\circ} \mathrm{C}$, and (f) $400^{\circ} \mathrm{C}$ and then following a post-annealing at $400^{\circ} \mathrm{C}$ for one hour.

\subsection{Optical properties}

Figure 5 shows the optical reflectance and transmittance spectra of the $\mathrm{ZnO}$ thin films obtained by preheating the sol at different temperatures for $10 \mathrm{~min}$ and then following a post-annealing at $400{ }^{\circ} \mathrm{C}$ for one hour. Clearly, an optical interference was observed in the reflectance spectra of the films. In terms of the film interference theory, the thickness of the films can be determined as $359.69,375.3,355.32,340.6,334.03$, and $327.21 \mathrm{~nm}$, respectively, for the films preheated at 150, 200, 250, 300,350 and $400{ }^{\circ} \mathrm{C}$. The optical transmittance spectra show that the average optical transmittance in the visible range is roughly increased and then decreased with increasing the preheating temperature, which was mainly due to the enhanced and the weakened strength of the $\langle 002\rangle$ preferred orientation, respectively. This result well agrees upon that reported elsewhere [19]. The average transmissivity in the visible region reached the maxima of $95 \%$ at the preheating temperature of $300^{\circ} \mathrm{C}$. In addition, the near-band absorption edge of the films has not 

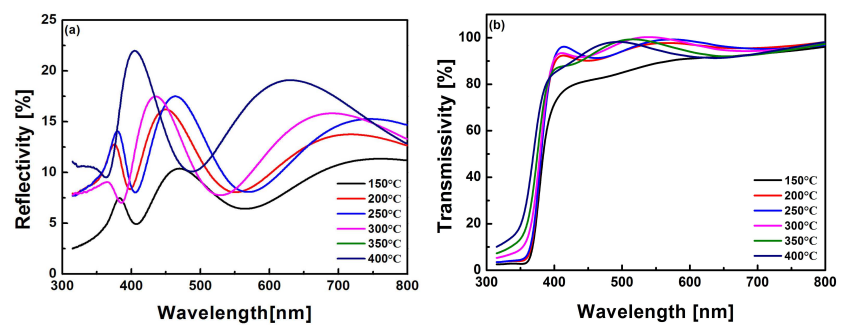

Fig. 5. Optical (a) reflectance and (b) transmittance spectra of the $\mathrm{ZnO}$ thin films obtained by preheating the sol at different temperatures for $10 \mathrm{~min}$ and then following a post-annealing at $400{ }^{\circ} \mathrm{C}$ for one hour.

a clear shift at the preheating temperature below $300^{\circ} \mathrm{C}$, however, obviously has a clear blue shift at the preheating temperature over $300^{\circ} \mathrm{C}$. The precise value of the absorption edge can be fitted in terms of the Tauc formula

$$
\alpha^{2}=\beta\left(E-E_{\text {opt }}\right),
$$

where $\alpha$ is the absorption coefficient near the absorption edge, $E$ and $E_{\text {opt }}$ are the photon energy and optical band gap, the linear parameter $\beta$ may be closely related to the defect content. The absorption coefficient $\alpha$ can be approximately calculated by using the formula (6):

$$
\alpha=(1 / d) \ln (1 / T),
$$

where $d$ and $T$ denote the film thickness and the optical transmissivity near the absorption edge, respectively.

Figure 6 shows the curves $\alpha^{2}(E)$ of the films. The extrapolation of the linear segments of the curves towards the $x$-axis can gives the absorption edge values of 3.28 , $3.26,3.26,3.30,3.31$, and $3.35 \mathrm{eV}$, respectively, for the films preheated at $150,200,250,300,350$, and $400^{\circ} \mathrm{C}$.

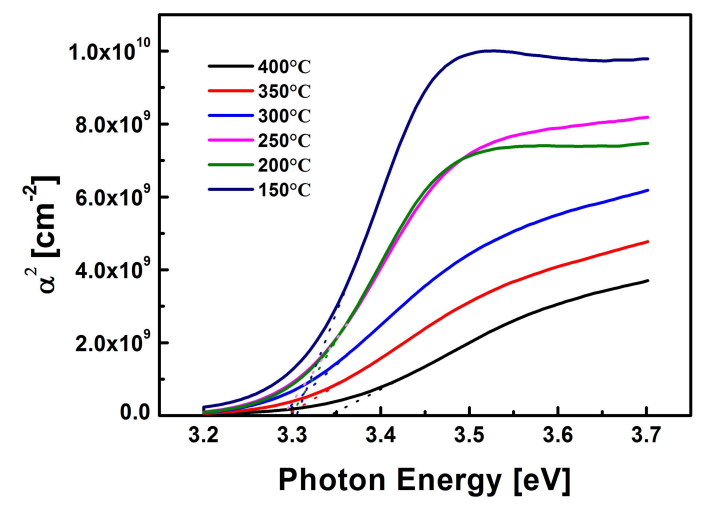

Fig. 6. The curves $\alpha^{2}(E)$ of the $\mathrm{ZnO}$ thin films obtained by preheating the sol at different temperatures for $10 \mathrm{~min}$ and then following a post-annealing at $400^{\circ} \mathrm{C}$ for one hour.

The slope of the linear segments of the curves is gradually reduced with the preheating temperature, indicating an increasing defect content. The absorption edge first redshifts and then blueshifts with increase of the preheating temperature. The red shift is closely related to the increasing microstress, while the blue shift can be explained in terms of quantum-size effect.

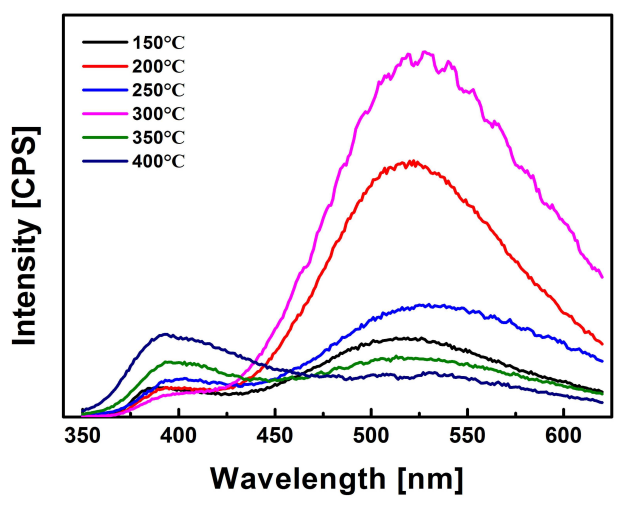

Fig. 7. Photoluminescence spectra of the $\mathrm{ZnO}$ thin films obtained by preheating the sol at different temperatures for $10 \mathrm{~min}$ and then following a post-annealing at $400^{\circ} \mathrm{C}$ for one hour.

Figure 7 shows the photoluminescence spectra of the $\mathrm{ZnO}$ thin films obtained by preheating the sol at different temperatures for $10 \mathrm{~min}$ and then following a postannealing at $400{ }^{\circ} \mathrm{C}$ for one hour. The excitation wavelength was $325 \mathrm{~nm}$. All the photoluminescence spectra exhibit two wide emission peaks of which one corresponds to the exciton-related ultraviolet emission and the other to the intrinsic defect-related green-yellow radiation at 470-620 nm. These broad emission peaks of $\mathrm{ZnO}$ thin films are related to the amount of non-stoichiometric intrinsic defects [29-31] and it originates from the zinc vacancy $\left(\mathrm{V}_{\mathrm{Zn}}\right)$ and antisite defects $\left(\mathrm{O}_{\mathrm{Zn}}\right)$ in $\mathrm{ZnO}$ films as reported by Wang et al. [32]. Seen from Fig. 7, the intensities of the green-yellow radiation is much larger than that of the exciton-related emission at the preheating temperature below $350^{\circ} \mathrm{C}$, indicating that the defect-related photoluminescence is initially dominated. With increasing the preheating temperature until $300^{\circ} \mathrm{C}$, the green-yellow radiation is clearly enhanced compared with the ultraviolet emission. This indicates that more intrinsic defects are produced at the stage due to the volatilization of the solvent and the decomposition of some residual organic species even though the $\langle 002\rangle$ preferred orientation of the thin film is enhanced. Especially, when the preheating temperature is over $300^{\circ} \mathrm{C}$, the intensity of the ultraviolet emission surpasses the intensity of the green-yellow radiation, indicating the content of the defects in the film is reduced. As shown in Fig. 7, the intrinsic photoluminescence of all the $\mathrm{ZnO}$ films is weak. This may be due to that the quality of the intrinsic $\mathrm{ZnO}$ thin films is not good enough.

\section{Mechanism for the preheating in the formation of the films}

From the above analysis it can be concluded that the preheating temperature has a strong influence on the microstructure and the photoluminescence of $\mathrm{ZnO}$ thin films. To get strong intrinsic photoluminescence, changing the preheating temperature alone is not enough. High preheating temperature needs higher postannealing temperature for the highly-oriented $\mathrm{ZnO}$ film. 
The preheating of the sol solution plays dual roles. One role is to make the sol be the gel by the volatilization of the solvent and the decomposition of the residual organic species. The other role is to prevent the film from shrinking. Too high preheating temperature can strongly accelerate the volatilization of the solvent and the decomposition of the residual organic species that can introduces more damages to the gel. Proper preheating temperature and post-annealing temperature is of importance to the preparation of the highly-oriented $\mathrm{ZnO}$ film by using sol-gel spin-coating technique.

\section{Conclusion}

The highly-oriented $\mathrm{ZnO}$ thin films were prepared on glass substrates by using sol-gel spin-coating technique. The effect of the preheating temperature was intensively investigated on the microstructure and the optical properties of the films. The mechanisms for the preheating in the formation of the films and for the reactions involved in the sol solution prepared by the two-step method were also proposed. With increasing the preheating temperature, the film tends to evolve from polycrystalline structure to $\langle 002\rangle$-oriented structure, and then to oriented-free structure. Simultaneously, the film surface evolves from uniform wrinkle-covered surface to homogeneous and dense surface with the preheating temperature. The $\langle 002\rangle$ orientation of the films reached strongest at the preheating temperature of $300^{\circ} \mathrm{C}$ that is proper to the preparation of the highly-oriented $\mathrm{ZnO}$ thin film. Too high preheating temperature is not favorable to the preparation of the highly-oriented $\mathrm{ZnO}$ thin film due to more damages introduced by the rapid volatilization of the solvent and the decomposition of the residual organic species. The near-violet absorption edges of the films obviously blue shift at the preheating temperature over $250^{\circ} \mathrm{C}$, which can be explained in terms of quantumsize effect. The photoluminescence spectra of the films show an exciton-related broad emission peak and an intrinsic defect-related green-yellow radiation peak. With increase of the preheating temperature, the film first shows a dominant green-yellow radiation and then shows a dominant intrinsic ultraviolet emission. The preheating plays dual roles in the formation of the gel. One role is to enhance the volatilization of the solvent and the decomposition of the residual organic species, the other role is, to some extent, to prevent the film from shrinking.

\section{References}

[1] S.J. Pearton, D.P. Norton, K. Ip, Y.W. Heo, T. Steiner, J. Vac. Sci. Technol. B 22, 932 (2004).

[2] Y.K. Mishra, S. Kaps, A. Schuchardt, I. Paulowicz, X. Jin, D. Gedamu, S. Wille, O. Lupan, R. Adelung, Kona Powder Part. J. 31, 92 (2014).

[3] V. Hrkac, L. Kienle, S. Kaps, A. Lotnyk, Y.K. Mishra, U. Schurmann, V. Duppel, B.V. Lotsch, R. Adelung, J. Appl. Crystallogr. 46, 396 (2013).

[4] Y.K. Tseng, C.J. Huang, H.M. Cheng, I.N. Lin, K.S. Liu, I.C. Chen, Adv. Funct. Mater. 13, 811 (2003).
[5] M.H. Mamat, Z. Khusaimi, M.Z. Musa, M.F. Malek, M. Rusop, Sens. Actuat. A 171, 241 (2011).

[6] M.H. Mamat, M.F. Malek, N.N. Hafizah, Z. Khusaimi, M.Z. Musa, M. Rusop, Sens. Actuat. B 195, 609 (2014).

[7] C.X. Xu, X.W. Sun, B.J. Chen, Appl. Phys. Lett. 84, 1540 (2004).

[8] A.M. Peiro, P. Ravirajan, K. Govender, D.S. Boyle, P. O'Brien, D.D.C. Bradley, J. Nelson, J.R. Durrant, J. Mater. Chem. 16, 2088 (2006).

[9] Y. Yoshino, T. Makino, Y. Katayama, T. Hata, Vacuum 59, 538 (2000).

[10] Z.W. Li, W. Gao, Mater. Lett. 58, 1363 (2004).

[11] K.H. Yoon, J.W. Choi, D.H. Lee, Thin Solid Films 302, 116 (1997).

[12] T. Ohshima, R.K. Thareja, T. Ikegami, K. Ebihara, Surf. Coat. Technol. 169-170, 517 (2003).

[13] T. Ohshima, T. Ikegami, K. Ebihara, J. Asmussen, R. Thareja, Thin Solid Films 435, 49 (2003).

[14] E.S. Shim, H.S. Kang, J.S. Kang, J.H. Kim, S.Y. Lee, Appl. Surf. Sci. 186, 474 (2002).

[15] J. Hu, R.G. Gordon, J. Appl. Phys. 72, 5381 (1992).

[16] B.M. Ataev, A.M. Bagamadova, V.V. Mamedov, A.K. Omaev, M.R. Rabadanov, J. Cryst. Growth 198-199, 1222 (1999).

[17] S. Fujihara, C. Sasaki, T. Kimura, Appl. Surf. Sci. 180, 341 (2001).

[18] J.H. Lee, K.H. Ko, B.O. Park, J. Cryst. Growth 247 , 119 (2003).

[19] Y.S. Kim, W.P. Tai, S.J. Shu, Thin Solid Films 491, 153 (2005).

[20] S. Rahimnejad, S.R. Setayesh, M.R. Gholami, J. Iran. Chem. Soc. 5, 367 (2008).

[21] Q.Z. Zhai, P. Wang, J. Iran. Chem. Soc. 5, 268 (2008).

[22] A.M.P. Santos, E.J.P. Santos, Thin Solid Films 516 , $6210(2008)$

[23] M. Ohyama, H. Kozuka, T. Yoko, Thin Solid Films 306, 78 (1997).

[24] D. H. Bao, H. S. Gu, A.X. Kuang, Thin Solid Films 312, 37 (1998).

[25] Q.M. Ji, X.Y. Gao, H. Gao, Y.F. Zhai, J. Zhengzhou Univ. (Natural Sci. Ed.), accepted, in press.

[26] JCPDS-International Centre for Diffraction Data, PCPDFWIN, version 6.0, 2000, 05-0664.

[27] S. Major, A. Banerjee, K.L. Chopra, Thin Solid Films 108, 333 (1983).

[28] Y. Natsume, H. Sakata, Thin Solid Films 372, 30 (2000).

[29] J. Aranovich, A. Ortiz, R.H. Bube, J. Vac. Sci. Technol. 16, 994 (1979).

[30] R. Ayouchi, F. Martin, D. Leinen, J.R. RamosBarrado, J. Cryst. Growth 247, 497 (2003).

[31] S. Yamauchi, Y. Goto, T. Hariu, J. Cryst. Growth 260, 1 (2004).

[32] J. Wang, G.T. Du, Y.T. Zhang, B.J. Zhao, X.T. Yang, D.L. Liu, J. Cryst. Growth 263, 269 (2004). 